\title{
Avaliação de contaminação por mercúrio em Descoberto, MG
}

\section{Evaluation of mercury contamination in Descoberto, $M G$}

\author{
Ana Amélia Paulino Tinôco \\ Engenheira Civil pela Universidade Federal do Rio Grande do Norte (UFRN). Doutoranda em Engenharia Civil pela Universidade Federal de Viçosa (UFV) \\ Izabel Christina d'Almeida Duarte de Azevedo \\ Engenheira Civil pela Pontifícia Universidade Católica do Rio de Janeiro (PUC-RIO). Doutora pela PUC-RIO. Professora Associada do Departamento \\ de Engenharia Civil da UFV
}

\section{Eduardo Antonio Gomes Marques}

Geólogo pela Universidade Federal do Rio de Janeiro (UFRJ). Doutor pela UFRJ. Professor Associado do Departamento de Engenharia Civil da UFV

\section{Ann Honor Mounteer}

Bióloga pela McGill University. Doutora pela UFV. Professora Adjunta do Departamento de Engenharia Civil da UFV

Cátia de Paula Martins

Engenheira Civil pela Universidade Federal de Juiz de Fora (UFJF). Doutoranda em Engenharia Civil da UFV

\section{Rejane Nascentes}

Engenheira Civil pela UFV. Doutora pela UFV. Professora Adjunta do Departamento de Engenharia Civil da UFV, Campus Rio Paranaíba

Efraim Lázaro Reis

Licenciado e Bacharel em Química pela UFV. Doutor pela Universidade Estadual de Campinas (UNICAMP). Professor Associado do Departamento de Química da UFV

\section{Ricardo Natalino}

Licenciado e Bacharel em Química pela UFV. Doutorando em Agroquímica da UFV

\begin{abstract}
Resumo
O mercúrio, elemento químico considerado não essencial a qualquer processo metabólico, é facilmente acumulado na maioria dos organismos. Ocorre naturalmente em formas orgânicas e inorgânicas, nos estados sólido, dissolvido e gasoso. Seu ciclo biogeoquímico envolve processos que ocorrem no solo, na água e na atmosfera. Em 2002, descobriu-se mercúrio elementar na zona rural do município de Descoberto, Minas Gerais, onde moram cerca de 70 famílias, e sua origem parece estar associada à exploração de ouro, que existiu na região no século 19. Neste trabalho, foram escolhidas três áreas para identificar possível contaminação da água, solo, sedimento e peixes por mercúrio, bem como para estabelecer valores de referência local e contraprova de resultados obtidos anteriormente. Verificaram-se elevadas concentrações no solo $\left(0,26\right.$ a 0,55 mg. $\left.\mathrm{kg}^{-1}\right)$, sedimentos $\left(0,13\right.$ a 0,61 mg. $\left.\mathrm{kg}^{-1}\right)$ e água $\left(<0,2\right.$ a 2,10 $\left.\mu \mathrm{g} \cdot \mathrm{L}^{-1}\right)$.
\end{abstract}

Palavras-chave: meio ambiente; contaminação por mercúrio; análises químicas.

\section{Abstract}

Mercury is a chemical element considered unessential to any metabolic process; however, it is easily accumulated in most organisms. It is naturally found in both organic and inorganic forms in solid, liquid and vapor states. Its biogeochemical cycle involves processes occurring in the soil, water and the atmosphere. In 2002, elementary mercury was found in the city of Descoberto, Minas Gerais, Brazil, where 70 families live, and its origin may be related to gold exploration that happened in this region in the $19^{\text {th }}$ century. In this work, three areas were chosen to identify a possible mercury contamination of water, soil, sediment and fish samples and to establish local reference values and counter-evidence of the data previously obtained. Based on the results, high mercury concentrations in soil $\left(0.26\right.$ to $\left.0.55 \mathrm{mg} \cdot \mathrm{kg}^{-1}\right)$, sediments $\left(0.13\right.$ to $\left.0.61 \mathrm{mg} \cdot \mathrm{kg}^{-1}\right)$ and water $\left(<0.2\right.$ to $\left.2,10 \mu \mathrm{g} \cdot \mathrm{L}^{-1}\right)$ were verified.

Keywords: environment; contamination by mercury; chemical analyses.

Endereço para correspondência: Ana Amélia Paulino Tinôco - Departamento de Engenharia Civil - Universidade Federal de Viçosa - Avenida P H Rolfs, 425, apto. 604 - Centro - 36570-000 - Viçosa (MG), Brasil - Tel.: (31) 3891-3426 - Fax (31) 3899-1481 - E-mail: tinocoana@hotmail.com

Recebido: 06/05/09 - Aceito: 28/05/10 - Reg. ABES: 05209 


\section{Introdução}

O mercúrio é um elemento químico considerado não essencial a qualquer processo metabólico; entretanto, é facilmente acumulado na maioria dos organismos. Ocorre naturalmente em formas orgânicas e inorgânicas, não só no estado sólido ou dissolvido, mas também na fase gasosa. Consequentemente, seu ciclo biogeoquímico envolve processos que ocorrem no solo, na água e na atmosfera (WINDMÖLLER et al., 2007).

Na superfície terrestre, o mercúrio é depositado no solo e em ambientes aquáticos. No solo, o tempo de retenção é longo, resultando em acúmulo desse elemento, o que pode acarretar seu lançamento nas águas, por meio de escoamento superficial e erosão.

No meio aquático, o mercúrio pode ser encontrado na água propriamente dita e nos sedimentos. Ao atingirem os ambientes aquáticos, as espécies inorgânicas do mercúrio podem sofrer reações mediadas, principalmente, por micro-organismos, que alteram seu estado inicial, resultando em compostos organomercuriais como o metilmercúrio, mais tóxico do que as espécies inorgânicas. O metilmercúrio é facilmente absorvido por peixes e outros animais aquáticos, o que leva à deposição dessa substância nos tecidos, acumulando-se ao longo do tempo e atingindo, na cadeia biológica, concentrações bem maiores do que as encontradas nas águas e nos sedimentos (AZEVEDO, 2003).

A presença de mercúrio no corpo humano pode ocasionar grandes danos à saúde. Devido à sua acumulação progressiva e irreversível, esse elemento fica retido nos tecidos, causando lesões graves, principalmente aos rins, fígado, aparelho digestivo e sistema nervoso central.

No Brasil, a questão da contaminação do meio ambiente é mais preocupante nas áreas de garimpo de ouro, atividade que representa uma das fontes emissoras de mercúrio antrópicas mais impactantes.

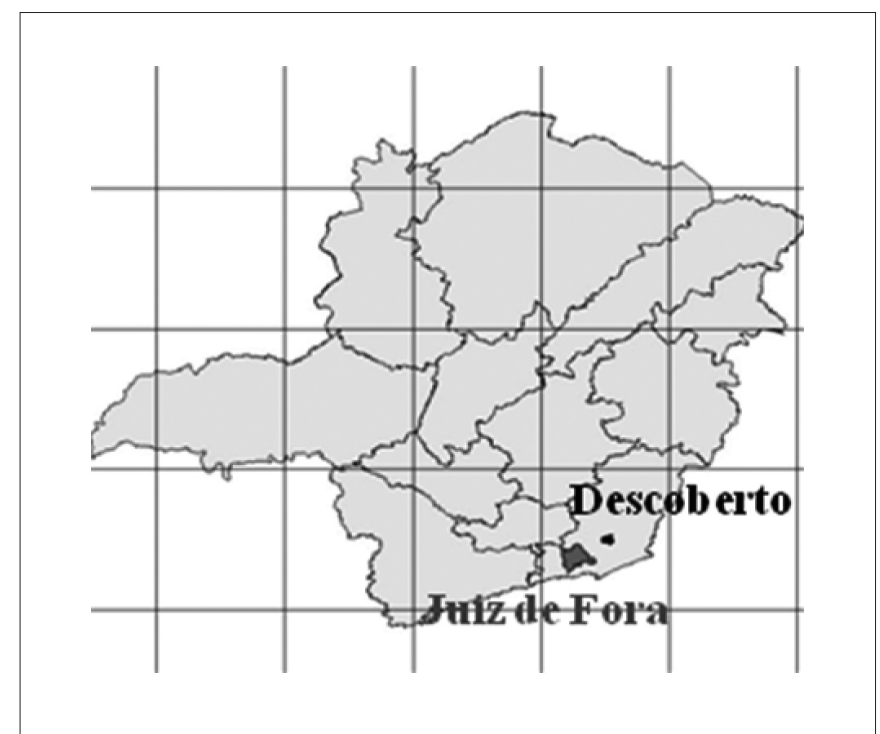

Figura 1 - Localização do município de Descoberto no mapa do Estado de Minas Gerais.
Essa atividade, que utiliza mercúrio elementar (líquido) na amalgamação do ouro, ocorre intensamente em vários estados do país e tem sido objeto e motivo de muitos trabalhos de investigação, denúncias e matérias jornalísticas.

Em dezembro de 2002, foi encontrado mercúrio elementar no município de Descoberto, na Zona da Mata do Estado de Minas Gerais (Figura 1), cuja origem parecia estar ligada à exploração de ouro que existiu na região, no século 19. Moradores da área rural, na localidade denominada Serra da Grama, perceberam a presença desse elemento quando foi realizado um corte em um terreno para a abertura de estrada de acesso a uma propriedade particular, que provocou o afloramento do mercúrio em sua forma líquida (Figura 2A) (MARQUES, 2007). O ponto de afloramento encontra-se a, aproximadamente, $20 \mathrm{~m}$ do córrego Rico, que deságua no ribeirão do Grama, pertencente à sub-bacia do rio Pomba e afluente da bacia do Paraíba do Sul (FEAM, 2005).

Na região afetada moram cerca de 70 famílias, totalizando, aproximadamente, 300 pessoas. A área no entorno do foco, com cerca de 450 ha, é constituída por Mata Atlântica, cachoeiras e diversas espécies de fauna e flora (Figura 2B). As águas da bacia do ribeirão do Grama são utilizadas para recreação, natação, pesca e dessedentação de animais. Além disso, o ribeirão era o principal manancial de abastecimento do núcleo urbano do município de Descoberto e de parte de São João Nepomuceno até dezembro de 2002. Desde essa data,

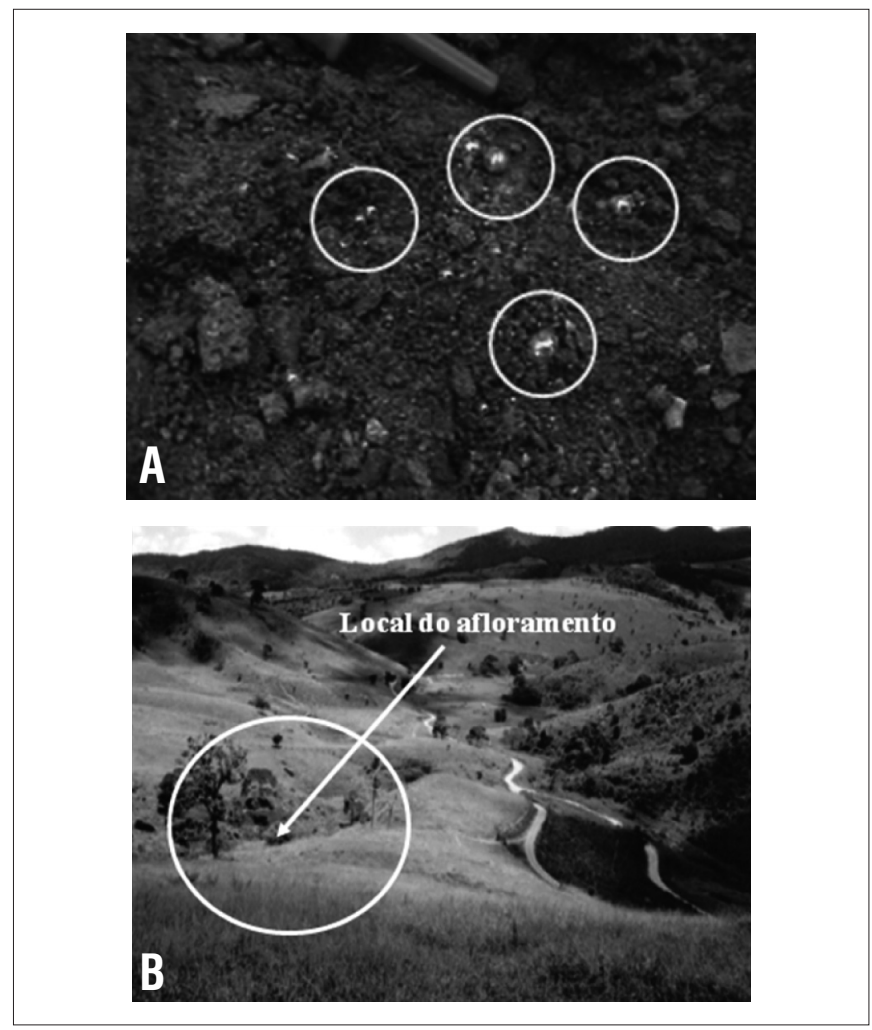

Figura 2 - (A) Detalhe do afloramento do mercúrio elementar no solo; (B) vista geral do vale do ribeirão do Grama - zona rural de Descoberto, onde ocorreu afloramento de mercúrio. 
a prefeitura municipal e a Companhia de Saneamento do Estado de Minas Gerais (Copasa) suspenderam a utilização das águas do ribeirão do Grama para abastecimento da população, quando foram informadas sobre o afloramento de mercúrio próximo a um afluente da bacia. Análises químicas de mercúrio total constataram elevada concentração desse elemento $\left(2,4 \mu \mathrm{g} \mathrm{L}^{-1}\right)$ em amostras de água na captação (FEAM, 2005).

Documentos que relatam especificamente a exploração de ouro na região de Descoberto são raros e, para que se compreenda, de modo geral, o cenário em que essa exploração ocorreu na região, é apresentado um breve resumo, com base em relatório da FEAM (2005).

Em meados do século 17, por determinação do governo, todo ouro, diamante e mercadorias deveriam ser transportados pelo chamado Caminho Novo, que ligava a região das minas ao Rio de Janeiro, visando com isso garantir o pagamento de impostos e encargos. Com o esgotamento das minas auríferas da província de Minas Gerais, a região situada a leste do Caminho Novo, compreendendo boa parte da atual Zona da Mata mineira, passou a ser cobiçada, na esperança de novas descobertas de ouro.

Em julho de 1824, o alemão Grigory Ivanovitch Langsdorff, expedicionário e cônsul-geral da Rússia no Brasil, esteve na região, onde hoje é o município de Descoberto, dois a quatro meses após a descoberta de ouro no local. Em seus diários, Langsdorff mencionou que o ouro foi encontrado pela primeira vez por um agricultor, num pequeno riacho em sua propriedade. A notícia espalhou-se em pouco tempo e trouxe para o local pessoas dos cantos mais remotos da província de Minas Gerais.

Há evidências de que, em algum momento, os mineradores utilizaram a amalgamação, com uso de mercúrio elementar, no processo de apuração do ouro (FEAM, 2005).

Segundo esse mesmo relatório, o modo de ocorrência do mercúrio na localidade está associado ao cascalho concentrado ao longo das canoas, estruturas que consistiam de um fosso pouco profundo, feito no solo, no lugar em que o minério era lavado sucessivamente com forte corrente de água, possibilitando a exclusão das porções mais lamacentas e retendo a porção mais densa, rica em ouro.

Dois cenários são possíveis para a contaminação. No primeiro, na apuração do ouro feita nas bateias, o mercúrio empregado na amalgamação (ou mesmo recuperado) foi armazenado em recipientes que foram abandonados no terreno. Com o passar do tempo, o mercúrio escorreu desses recipientes, espalhou-se pelo subsolo e escoou pelas antigas canoas. No segundo, o mercúrio foi lançado direto nas canoas, juntamente com as águas de lavagem dos cascalhos, no processo de recuperação da porção fina do ouro. Nesse contexto, no primeiro caso, a presença do mercúrio no solo teria origem acidental e, no segundo, sua presença ao longo das canoas seria parte do processo de apuração do ouro empregado na área.
Em razão da descoberta de mercúrio elementar na zona rural do município, vários estudos têm sido desenvolvidos na área do afloramento e da vizinhança, no intuito de dimensionar a contaminação ambiental no local.

A FEAM (2005) analisou a concentração de mercúrio em compartimentos como solo, água, sedimentos, entre outros, em área próxima ao córrego Rico, na vizinhança do foco inicial da contaminação e no ribeirão do Grama.

Em relação às águas, apenas as amostragens realizadas em dezembro de 2002 e em março de 2004 indicaram concentrações anormais de 2,4 e 0,3 $\mu \mathrm{g} . \mathrm{L}^{-1}$, respectivamente, desse elemento no ponto de captação das águas do ribeirão do Grama para abastecimento.

Nos sedimentos, as análises foram realizadas em seis pontos, quatro no córrego Rico, próximo ao local do afloramento, e dois no ribeirão do Grama. Determinaram-se concentrações entre 0,18 e 0,46 mg. $\mathrm{kg}^{-1}$ nas amostras coletadas no córrego Rico e entre 0,0566 e 0,0607 mg.kg-1 nas amostras do ribeirão do Grama.

No solo, foram avaliadas 61 amostras, em que se detectaram os valores mínimo e máximo, respectivamente, de 0,196 e 8825,8 mg. $\mathrm{kg}^{-1}$, com mediana igual a 1,86 mg. $\mathrm{kg}^{-1}$, ressaltando-se que 93\% (57 amostras) dos resultados superaram o valor de referência local de 0,30 mg. $\mathrm{kg}^{-1}$ estabelecido pela FEAM (2005).

Novos afloramentos foram observados ao longo do processo de coleta das amostras na área do afloramento inicial, tendo-se constatado visualmente que o mercúrio estava em um compartimento de cascalho (conduto) que fazia parte do processo de concentração de ouro utilizado durante o período de lavra desse metal (FEAM, 2005)

Alexandre (2006) analisou 23 amostras de água, em 3 campanhas de coleta: 2 no período chuvoso e 1 no período seco. A máxima concentração de mercúrio encontrada foi de 4,3 $\mu \mathrm{g}$. $\mathrm{L}^{-1}$ no período chuvoso. Na amostra coletada no ponto de captação de água da Copasa, no ribeirão do Grama, a concentração foi de 2,8 $\mu \mathrm{g} . \mathrm{L}^{-1}$. No caso dos sedimentos, o plano de amostragem consistiu em analisar o nível de mercúrio em seis pontos, em diversas profundidades, tendo-se obtido valores variando entre 0,03 e 0,51 mg.kg-1. No solo, as amostras foram coletadas em uma área a jusante do foco inicial do afloramento, a qual, segundo moradores da região, era o local onde teria havido garimpagem de ouro. As análises realizadas em 15 amostras, em diversas profundidades, apresentaram concentrações máximas de 0,346 mg. $\mathrm{kg}^{-1}$.

Os resultados de estudos realizados até então (ALEXANDRE, 2006; FEAM, 2005) confirmaram a existência de concentrações significativas de mercúrio nas águas do ribeirão do Grama, bem como nos solos e sedimentos dessa microbacia.

Neste trabalho, escolheram-se três áreas: duas (A e B) potencialmente contaminadas para identificar a concentração de mercúrio em amostras de água, solo, sedimento e peixes; e uma terceira (C) para estabelecer valores de referência local em amostras de sedimentos e 
solo. Na área A, determinou-se também a contraprova de resultados obtidos anteriormente em análises de sedimentos na região.

\section{Metodologia}

\section{Área de estudo}

Definiram-se três áreas de interesse: a área A, estudada por Alexandre (2006) na calha do ribeirão do Grama, situada a jusante do local onde houve afloramento de mercúrio em 2002 e a montante da captação de água da Copasa; a área B é uma propriedade particular, próxima ao perímetro urbano e cortada pelo córrego Rico, que deságua no córrego das Pedras; e a área C, nas proximidades do

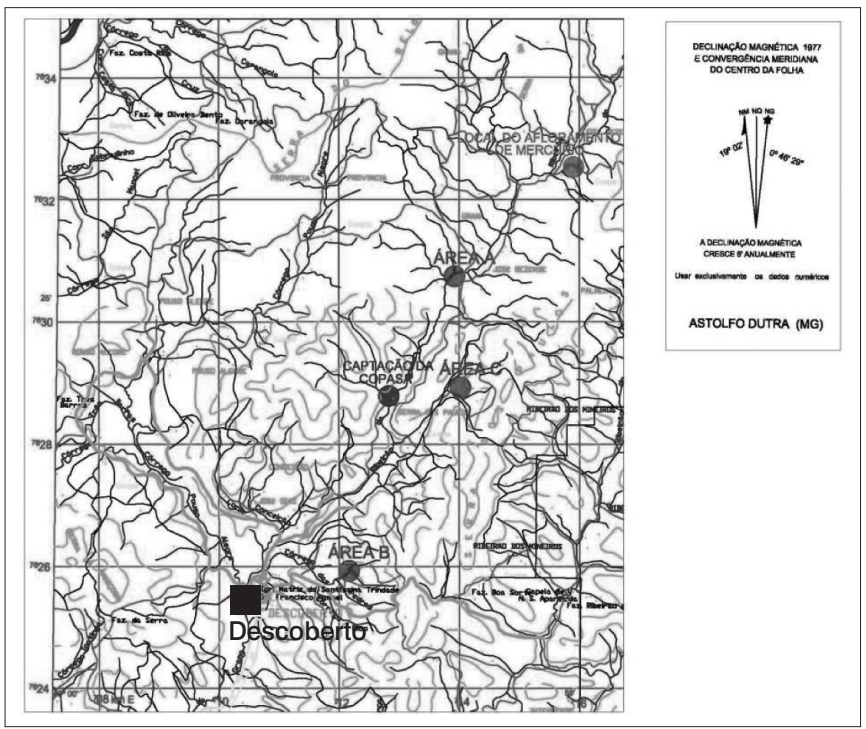

Figura 3 - Mapa de localização das áreas estudadas. ribeirão do Ronca, que faz parte da bacia do ribeirão do Grama, foi escolhida para se estabelecerem referências locais para o solo e sedimentos. Contudo, as análises químicas iniciais indicaram concentrações significantes de mercúrio nos pontos amostrados, o que fez com que essa área fosse incluída como objeto de estudo e descartada como referência local.

Na Figura 3 e na Tabela 1, apresenta-se o mapa de localização das áreas estudadas, bem como as coordenadas geográficas dos pontos de coleta em Universal Transversa de Mercator (UTM), respectivamente.

\section{Campanhas de amostragem}

Realizaram-se quatro campanhas de amostragem:

- $\quad 1^{\text {a }}$ campanha (Março/2007) - amostras de água e sedimentos nas áreas A e B; amostras de água da rede de distribuição em estabelecimentos comerciais do município;

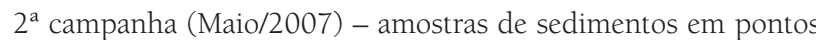
específicos da calha do ribeirão do Grama para servirem de contraprova dos resultados obtidos nos sedimentos por Alexandre (2006); na área C, colheram-se amostras de água e sedimentos (para estabelecer referências locais) e amostras de peixes;

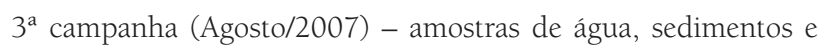
solo na área $C$, devido às significativas concentrações de mercúrio encontradas por ocasião da realização da campanha anterior e amostras de água da Estação de Tratamento de Água da Copasa, consumida pelos moradores e captada em uma mina situada na área urbana do município;

$4^{\text {a }}$ campanha (Dezembro/2007) - amostras de água, sedimentos e solos nas áreas A, B e C; amostras de água consumida pelos

Tabela 1 - Coordenadas geográficas em Universal Transversa de Mercator (UTM) dos pontos de coleta

\begin{tabular}{|c|c|c|c|}
\hline Amostra & Coordenadas & Amostra & Coordenadas \\
\hline \multirow{2}{*}{$A_{1}$} & E 714.140 & \multirow{2}{*}{$\mathrm{B}_{7}$} & E 7120.63 \\
\hline & N 7.630.879 & & N 7.625.650 \\
\hline \multirow{2}{*}{$\mathrm{A}_{2}$} & E 714.125 & \multirow{2}{*}{$C_{1}$} & E 714.329 \\
\hline & N 7.630.877 & & N 7.629.599 \\
\hline \multirow{2}{*}{$\mathrm{A}_{3}$} & E 714.107 & \multirow{2}{*}{$\mathrm{C}_{2}$} & E 713.759 \\
\hline & N 7.630.843 & & N 7.628.831 \\
\hline \multirow{2}{*}{$\mathrm{B}_{1}$} & E 711.927 & \multirow{2}{*}{$\mathrm{C}_{3}$} & E 714.409 \\
\hline & N 7.625.788 & & N 7.629.562 \\
\hline \multirow{2}{*}{$\mathrm{B}_{2}$} & E 711.952 & \multirow{2}{*}{$\mathrm{C}_{4}$} & E 714.347 \\
\hline & N 7.625.801 & & N 7.629.568 \\
\hline \multirow{2}{*}{$\mathrm{B}_{3}$} & E 711.986 & \multirow{2}{*}{$\mathrm{CP}_{1}$} & E 715.431 \\
\hline & N 7.625.824 & & N 7.632.403 \\
\hline \multirow{2}{*}{$\mathrm{B}_{4}$} & E 712.023 & \multirow{2}{*}{$\mathrm{CP}_{2}$} & E 714.107 \\
\hline & N 7.625.828 & & N 7.630 .843 \\
\hline \multirow{2}{*}{$\mathrm{B}_{5}$} & E 712.011 & \multirow[b]{2}{*}{$\mathrm{CP}_{3}$} & E 712.841 \\
\hline & N 7.625.795 & & N 7.628.760 \\
\hline \multirow{2}{*}{$\mathrm{B}_{6}$} & E 712.051 & & \\
\hline & N 7.625.728 & & \\
\hline
\end{tabular}


moradores captadas em uma mina situada na área urbana do município e amostras de peixes.

\section{Coleta e preservação das amostras}

\section{Água superficial}

As amostras foram coletadas em triplicata, com o auxílio de uma haste coletora, a profundidades entre 15 e $30 \mathrm{~cm}$, transferidas para frascos de polietileno com capacidade de 0,5 L, etiquetados, tampados e descontaminados em laboratório com solução de $\mathrm{HNO}_{3}$ a $10 \%$, água deionizada e ambientados com água do local de coleta. Para preservá-las, as amostras foram previamente filtradas em membrana de acetato de celulose com porosidade de 0,45 $\mu \mathrm{m}$, acidificadas com $\mathrm{HNO}_{3}$ para que o valor do $\mathrm{pH}$ fosse menor do que 2 (APHA, AWWA, WEF, 1995) e mantidas sob resfriamento em caixas térmicas com gelo até a chegada ao laboratório, onde foram acondicionadas em geladeira a $4^{\circ} \mathrm{C}$ e, posteriormente, encaminhadas para análise (MARINS et al., 2004).

\section{Peixes}

Alguns exemplares das espécies Astyanax scabripinnis (Lambari), Geophagus brasiliensis (Acará) e Hoplias malabaricus (Traíra) foram pescados em uma represa situada na área $C$ para análise de mercúrio total. Os peixes foram armazenados em sacos plásticos e transportados resfriados em caixa térmica. Na chegada ao laboratório, as amostras foram imediatamente encaminhadas para análise.

\section{Sedimentos}

As amostras foram coletadas no leito dos rios, manualmente, com espátula de teflon ${ }^{\circledR}$, a profundidades $\leq 10 \mathrm{~cm}$, transferidas para sacos plásticos etiquetados e mantidas sob resfriamento em gelo em caixas térmicas até a chegada ao laboratório, onde foram armazenadas em geladeira a $4^{\circ} \mathrm{C}$ e, posteriormente, encaminhadas para análise. A coleta foi realizada, preferencialmente, em locais de pouca profundidade e menor velocidade de fluxo, onde ocorreu a sedimentação do material em suspensão.

\section{Solo}

As amostras de solo foram retiradas das camadas superficiais ( $\leq$ $20 \mathrm{~cm}$ ), com trado de aço. Empregou-se o mesmo procedimento adotado com relação aos sedimentos no acondicionamento, transporte e armazenamento dessas amostras.

\section{Procedimentos de laboratório}

No preparo das soluções utilizou-se água deionizada, e os reagentes foram de grau de pureza para análise. As análises foram realizadas em triplicata, incluindo um branco de reagentes para detectar possíveis contaminações. Usou-se vidraria comum de laboratório, após prévio tratamento para descontaminação de metais, que consistiu em imersão por, no mínimo, 24 horas em banho de ácidos (ácido nítrico concentrado, ácido clorídrico concentrado e água deionizada, na proporção 1:1:3) tendo sido, em seguida, lavada com água deionizada.

Nas análises de mercúrio total, utilizou-se um espectrofotômetro de absorção atômica (EspectrAA-200), acoplado a um gerador de vapor a frio (CVAAS) (VGA77), ambos de fabricação Varian, Inc., USA. Para verificação da qualidade analítica dos resultados, as leituras foram refeitas em um espectrômetro de emissão de plasma Optima 3300 TV (Perkin Elmer ${ }^{\circledR}$, USA).

\section{Mercúrio total em água}

O procedimento para determinar a quantidade de mercúrio total em água consistiu nos seguintes passos: (1) pipetar $100 \mathrm{~mL}$ da amostra; (2) colocar a amostra em banho de gelo e adicionar $10 \mathrm{~mL}$ de ácido sulfúrico $\left(\mathrm{H}_{2} \mathrm{SO}_{4}\right) ;(3)$ adicionar $2 \mathrm{~mL}$ de permanganato de potássio $\left(\mathrm{KMnO}_{4}\right) 5 \%(\mathrm{~m} / \mathrm{v})$; (4) colocar em banho-maria a $95^{\circ} \mathrm{C}$ por 1 hora; (5) adicionar $1 \mathrm{~mL}$ de persulfato de potássio $\left(\mathrm{K}_{2} \mathrm{~S}_{2} \mathrm{O}_{8}\right)$ em banho de gelo; (6) após esfriar, filtrar; e (7) adicionar $5 \mathrm{~mL}$ de cloridrato de hidroxilamina $\left(\mathrm{NH}_{2} \mathrm{OH} . \mathrm{HCl}\right) 5 \%(\mathrm{~m} / \mathrm{v})$ no momento de fazer a leitura.

\section{Mercúrio total em sedimentos e solo}

O procedimento adotado, adaptado de Malm (1989), pode ser descrito sucintamente como se segue: (1) pesar cerca de $1 \mathrm{~g}$ da amostra; (2) colocar em banho de gelo (para evitar a volatilização do mercúrio) e adicionar $15 \mathrm{~mL}$ de uma mistura de ácido sulfúrico e ácido nítrico $\left(\mathrm{H}_{2} \mathrm{SO}_{4} / \mathrm{HNO}_{3}\right)(2: 1)(\mathrm{v} / \mathrm{v})$ - caso a amostra apresente alto teor de matéria orgânica, adicionar mais $10 \mathrm{~mL}$ da mesma mistura; (3) colocar em banho-maria a $60^{\circ} \mathrm{C}$ até obter uma suspensão clara (30 minutos); (4) adicionar, em banho de gelo, cerca de $15 \mathrm{~mL}$ de permanganato de potássio $\left(\mathrm{KMnO}_{4}\right) 5 \%(\mathrm{~m} / \mathrm{v})$, com leve agitação, e deixar em repouso por 15 minutos; (5) adicionar $5 \mathrm{~mL}$ de persulfato de potássio $\left(\mathrm{K}_{2} \mathrm{~S}_{2} \mathrm{O}_{8}\right) 5 \%(\mathrm{~m} / \mathrm{v})$ e colocar em banho-maria por 2 horas a $95^{\circ} \mathrm{C}$; e (6) deixar esfriar, filtrar e adicionar $6 \mathrm{~mL}$ de cloridrato de hidroxilamina $\left(\mathrm{NH}_{2} \mathrm{OH} . \mathrm{HCl}\right) 5 \%(\mathrm{~m} / \mathrm{v})$ no momento de fazer a leitura.

\section{Mercúrio total em peixes}

As análises de mercúrio total em peixes foram realizadas em base seca, seguindo-se o procedimento adaptado de Malm (1989), que consistiu nas seguintes etapas: (1) pesar $2 \mathrm{~g}$ da amostra seca a $60^{\circ} \mathrm{C}$; (2) adicionar $2 \mathrm{~mL}$ de peróxido de hidrogênio $\left(\mathrm{H}_{2} \mathrm{O}_{2}\right) 30 \%$ em duas etapas $(1+1)$; (3) após 10 minutos, colocar em banho de gelo e adicionar $15 \mathrm{~mL}$ de ácido sulfúrico $\left(\mathrm{H}_{2} \mathrm{SO}_{4}\right)$ em duas etapas $(7,5+7,5$ $\mathrm{mL})$; (4) aquecer por 15 minutos a $60^{\circ} \mathrm{C}$ e esfriar em banho de gelo; (5) adicionar $30 \mathrm{~mL}$ de permanganato de potássio $\left(\mathrm{KMnO}_{4}\right)$ 5\%; (6) aquecer em banho de água $\left(60^{\circ} \mathrm{C}\right)$ por 30 minutos; (7) deixar esfriar e adicionar $40 \mathrm{~mL}$ de persulfato de potássio $\left(\mathrm{K}_{2} \mathrm{~S}_{2} \mathrm{O}_{8}\right) 5 \%$; e (8) deixar em repouso por uma noite e adicionar $5 \mathrm{~mL}$ de cloridrato de hidroxilamina $\left(\mathrm{NH}_{2} \mathrm{OH} . \mathrm{HCl}\right) 12 \%$ para se proceder à leitura. 


\section{Preparo da curva padrão}

A curva padrão foi estabelecida utilizando-se soluções com concentrações de 0,5, 1, 2, 5, 10 e $30 \mu \mathrm{g} \cdot \mathrm{L}^{-1}$, obtidas a partir de solução com concentração de $1.000 \mathrm{mg} . \mathrm{L}^{-1}$, de acordo com a metodologia de Malm (1989) e do catálogo do espectrofotômetro de absorção atômica. A curva analítica foi preparada em ácido clorídrico ( $\mathrm{HCl}$ ) 10\% (v/v). No momento da leitura, foi necessário utilizar ácido clorídrico ( $\mathrm{HCl}) 5 \mathrm{~mol} . \mathrm{L}^{-1}$ e boroidreto de sódio $\left(\mathrm{NaBH}_{4}\right)$ 0,3\% em hidróxido de sódio (NaOH) 0,5\%.

\section{Resultados e discussão}

Apresentam-se os resultados das análises de mercúrio total em amostras de água coletadas nas áreas A, B e C, em pontos da rede de abastecimento, na estação de tratamento de água (ETA) e em uma mina. Os resultados, dispostos em ordem cronológica, são apresentados na Tabela 2 .

A resolução Conama n ${ }^{\circ}$ 357/2005 estabelece o valor máximo permitido para corpos de água Classe 2, na qual se encontram os corpos de água ainda não enquadrados, tal como em estudo, de 0,2 $\mu$ g. L-1 .

Com base nas análises realizadas nas quatro campanhas, observou-se que as concentrações de mercúrio na água apresentaram variação, de um valor menor que 0,2 a 2,10 $\mu \mathrm{g} \cdot \mathrm{L}^{-1}$. De modo geral, as concentrações de mercúrio oscilaram nas campanhas, uma vez que os níveis de metais dissolvidos na água são extremamente variáveis. Segundo Tomazelli (2003), a avaliação dessa variável isoladamente fornece pouca informação sobre a contaminação do ambiente.
Desse modo, é essencial avaliar esses resultados, relacionando-os com os obtidos em outras matrizes, a exemplo dos sedimentos.

Nas amostras de água da rede de abastecimento coletadas em estabelecimentos comerciais do município, não se detectou a presença de mercúrio.

$\mathrm{Na}$ área $\mathrm{C}$, escolhida inicialmente para servir de referência local para o solo e sedimentos, verificaram-se, na segunda campanha, elevadas concentrações de mercúrio na água no ponto $C_{1}$. Por esse motivo, repetiu-se a coleta nessa área na terceira campanha, ampliando-se os pontos de amostragem.

$\mathrm{Na}$ quarta campanha, as concentrações de mercúrio nos pontos $A_{1}, A_{2}, B_{5}, B_{6}, B_{7}$ e $C_{2}$ foram superiores ao valor máximo de $0,2 \mu \mathrm{g} . \mathrm{L}^{-1}$ estabelecido na resolução Conama no 357/2005. Acredita-se que a elevação das concentrações nessa campanha possa estar associada ao período de chuvas e, consequentemente, ao maior volume de água percolado, que pode ter provocado maior lixiviação do mercúrio presente no solo e maior quantidade de material em suspensão na coluna de água, condição refletida nos elevados valores de desvio padrão.

No que se refere às variáveis físicas e químicas medidas in situ ( $\mathrm{pH}$, condutividade elétrica e temperatura), não se verificaram grandes variações nas quatro campanhas.

Em relação ao pH, com exceção das amostras coletadas na mina na terceira $(5,64 \pm 0,04)$ e quarta $(5,59 \pm 0,02)$ campanhas, os valores medidos nas quatro campanhas variaram entre 6,70 $\pm 0,02 \mathrm{e}$ $7,94 \pm 0,01$ e encontravam-se dentro dos limites estabelecidos pela resolução Conama 357/05 para águas de Classe 2

Tabela 2 - Concentração de mercúrio total em água

\begin{tabular}{|c|c|c|c|c|}
\hline \multirow[t]{2}{*}{ Amostras } & \multicolumn{4}{|c|}{ Concentração $\left(\mu \mathrm{g} \cdot \mathrm{L}^{-1}\right)^{(\mathrm{a})}$} \\
\hline & $1^{\text {a }}$ Campanha & $2^{\text {a }}$ Campanha & $3^{\text {a }}$ Campanha & $4^{\mathrm{a}}$ Campanha \\
\hline$A_{1}{ }^{(b)}$ & $<\mathrm{LD}$ & - & - & $0,37 \pm 0,19$ \\
\hline $\mathrm{A}_{2}$ & $<$ LD & - & - & $0,30 \pm 0,15$ \\
\hline $\mathrm{A}_{3}$ & $<$ LD & - & - & $<$ LD \\
\hline $\mathrm{B}_{1}{ }^{(\mathrm{c})}$ & $<$ LD & - & - & - \\
\hline $\mathrm{B}_{2}$ & $0,49 \pm 0,10$ & - & - & - \\
\hline $\mathrm{B}_{3}$ & $<$ LD & - & - & - \\
\hline $\mathrm{B}_{4}$ & $<\mathrm{LD}$ & - & - & $<$ LD \\
\hline $\mathrm{B}_{5}$ & $<$ LD & - & - & $0,76 \pm 0,14$ \\
\hline$B_{6}$ & $<$ LD & - & - & $0,43 \pm 0,14$ \\
\hline $\mathrm{B}_{7}$ & $<$ LD & - & - & $0,50 \pm 0,18$ \\
\hline $\mathrm{C}_{1}{ }^{(\mathrm{d})}$ & - & $0,93 \pm 0,30$ & $<$ LD & $<\mathrm{LD}$ \\
\hline $\mathrm{C}_{2}$ & - & $<$ LD & $0,35 \pm 0,04$ & $0,61 \pm 0,21$ \\
\hline $\mathrm{C}_{3}$ & - & - & $<\mathrm{LD}$ & $<$ LD \\
\hline $\mathrm{C}_{4}$ & - & - & $2,10 \pm 0,28$ & - \\
\hline Bar & $<$ LD & - & - & - \\
\hline Padaria & $<$ LD & - & - & - \\
\hline Restaurante & $<\mathrm{LD}$ & - & - & - \\
\hline ETA (bruta) ${ }^{(e)}$ & - & - & $<$ LD & - \\
\hline ETA (Tratada) & - & - & $<\mathrm{LD}$ & - \\
\hline Mina & - & - & $<$ LD & $<\mathrm{LD}$ \\
\hline
\end{tabular}

(a) média de três repetições \pm desvio padrão; (b) $A_{1}$ a $A_{3}$ : amostras coletadas na área $A$; (c) $B_{1}$ a $B_{7}$ : amostras coletadas na área $B$; (d) $C_{1}$ a $C_{4}$ : amostras coletadas na área $C$; (e) ETA: estação de tratamento de água; < LD: indica menor que o limite de detecção do método $\left(0,2 \mu \mathrm{g} \cdot \mathrm{L}^{-1}\right)$. 
As variações de temperatura fazem parte do regime climático normal, e os corpos de água naturais apresentam variações sazonais e diurnas, bem como estratificação vertical, sendo a temperatura superficial influenciada por fatores como latitude, estação do ano, período do dia e vazão (LIMA, 2005). As variações da temperatura (19,4 \pm 0,00 a 28,95 $\pm 0,00^{\circ} \mathrm{C}$ ) podem ser justificadas pelo fato de as amostras terem sido coletadas em épocas distintas do ano e em diferentes períodos do dia.

Em águas naturais, podem ser encontradas faixas de condutividade elétrica na ordem de 0,01 e 0,1 dS.m ${ }^{-1}$. A condutividade elétrica variou entre 0,021 $\pm 0,000$ e 0,175 $\pm 0,000 \mathrm{dS} . \mathrm{m}^{-1}$. Valores acima de $0,1 \mathrm{dS} \cdot \mathrm{m}^{-1}$ foram observados apenas em pontos da ETA (tratada) $\left(0,175 \pm 0,000 \mathrm{dS} \cdot \mathrm{m}^{-1}\right)$ e da rede de distribuição, padaria $(0,152 \pm$ 0,000 dS. $\left.\mathrm{m}^{-1}\right)$ e restaurante $\left(0,157 \pm 0,000 \mathrm{dS} . \mathrm{m}^{-1}\right)$. Dessa forma, determinaram-se as concentrações de alguns íons na água em pontos da rede de distribuição, em que se verificou que a concentração de cálcio nas amostras da padaria $\left(20,42 \mathrm{mg} . \mathrm{L}^{-1}\right)$ e do restaurante $(19,53$ $\left.\mathrm{mg} . \mathrm{L}^{-1}\right)$ parecia ter contribuído para a elevação da condutividade elétrica. Parte dessa concentração pode ser atribuída à cal hidratada utilizada na regularização do pH durante o tratamento físico-químico a que a água foi submetida antes de sua distribuição.

$\mathrm{Na}$ Tabela 3, encontram-se os resultados das análises de mercúrio nos sedimentos. Nesse compartimento, os valores estabelecidos pela legislação canadense e adotados pela resolução Conama 344/2004 definem duas concentrações limite: $0,17 \mathrm{mg} \cdot \mathrm{kg}^{-1}$, valor abaixo do qual raramente são esperados efeitos adversos à biota; e 0,486 mg. $\mathrm{kg}^{-1}$, acima do qual esses efeitos são frequentemente observados. Verifica-se, nessa tabela, que a concentração de mercúrio na maioria das amostras situava-se na faixa definida pelos dois limites, intervalo em que ocasionalmente esperam-se efeitos adversos aos organismos. Apenas nas amostras do ponto $C_{1}$ foram encontradas concentrações acima do limite, em que frequentemente ocorrem efeitos adversos à biota e, por isso, a área C foi descartada como referência local e incluída como de interesse no estudo.

$\mathrm{Na}$ campanha de contraprova, as concentrações detectadas de mercúrio foram superiores às obtidas por Alexandre (2006), utilizando-se a mesma metodologia. Entretanto, essa diferença não foi significativa, uma vez que os valores obtidos situavam-se na faixa em que ocasionalmente podem ocorrer efeitos adversos à biota.

Observou-se que as concentrações relativamente elevadas de mercúrio nos sedimentos na bacia do ribeirão do Grama não estavam restritas ao domínio em que ocorreu o afloramento, uma vez que as áreas estudadas estavam distantes do foco inicial da contaminação e, portanto, fora de seu campo de ação. Dessa forma, confirmou-se a existência de níveis consideráveis desse elemento nos sedimentos em outros pontos da bacia.

É aceitável a hipótese de que a contaminação dos sedimentos por mercúrio tenha sido provocada pelo processo de beneficiamento do ouro desenvolvido no local até o início do século passado, apesar do tempo decorrido desde a sua interrupção. De acordo com Azevedo (2003), o fato de a atividade antrópica ser transferida de local ou encerrada não impede que o mercúrio acumulado em sua decorrência possa continuar presente por muitos anos e, assim, os efeitos associados a essa acumulação nos organismos também se arrastarão por longos períodos.

Provavelmente, a dispersão de mercúrio por fontes difusas não pontuais, como a deposição atmosférica, também contribuiu para a elevação da concentração desse elemento nos sedimentos. A importância dessas fontes no ambiente aquático tem sido cada vez mais enfatizada, uma vez que a atmosfera desempenha importante papel de corpo receptor desse metal, tanto das emissões naturais quanto das antrópicas (MARINS et al., 2004).

Tabela 3 - Concentração de mercúrio total em sedimentos

\begin{tabular}{|c|c|c|c|c|}
\hline \multirow[t]{2}{*}{ Amostras } & \multicolumn{4}{|c|}{ Concentração $\left(\mathrm{mg}^{\mathrm{kg}}{ }^{-1}\right)^{(\mathrm{a})}$} \\
\hline & $1^{\text {a }}$ Campanha & $2^{\mathrm{a}}$ Campanha & $3^{a}$ Campanha & $4^{\mathrm{a}}$ Campanha \\
\hline$A_{1}{ }^{(b)}$ & $0,20 \pm 0,01$ & - & - & $0,37 \pm 0,02$ \\
\hline $\mathrm{A}_{2}$ & $0,21 \pm 0,02$ & - & - & $0,33 \pm 0,01$ \\
\hline $\mathrm{A}_{3}$ & $0,22 \pm 0,01$ & - & - & $0,25 \pm 0,01$ \\
\hline $\mathrm{B}_{1}{ }^{(\mathrm{c})}$ & $0,14 \pm 0,01$ & - & - & - \\
\hline $\mathrm{B}_{2}$ & $0,13 \pm 0,02$ & - & - & - \\
\hline $\mathrm{B}_{3}$ & $0,14 \pm 0,01$ & - & - & - \\
\hline $\mathrm{B}_{4}$ & $0,18 \pm 0,01$ & - & - & $0,36 \pm 0,10$ \\
\hline $\mathrm{B}_{5}$ & $0,38 \pm 0,09$ & - & - & $0,42 \pm 0,01$ \\
\hline$B_{6}$ & $0,29 \pm 0,01$ & - & - & $0,33 \pm 0,01$ \\
\hline $\mathrm{B}_{7}$ & $0,29 \pm 0,07$ & - & - & $0,35 \pm 0,03$ \\
\hline $\mathrm{C}_{1}{ }^{(\mathrm{d})}$ & - & $0,31 \pm 0,02$ & $0,52 \pm 0,01$ & $0,61 \pm 0,03$ \\
\hline $\mathrm{C}_{2}$ & - & $0,43 \pm 0,08$ & $0,32 \pm 0,02$ & $0,43 \pm 0,01$ \\
\hline $\mathrm{C}_{3}$ & - & - & $0,37 \pm 0,02$ & - \\
\hline $\mathrm{C}_{4}$ & - & - & $0,37 \pm 0,02$ & - \\
\hline $\mathrm{CP}_{1}{ }^{(\mathrm{e})}$ & - & $0,28 \pm 0,01$ & - & - \\
\hline $\mathrm{CP}_{2}$ & - & $0,26 \pm 0,04$ & - & - \\
\hline $\mathrm{CP}_{3}$ & - & $0,15 \pm 0,07$ & - & - \\
\hline
\end{tabular}

(a) média de três repetições \pm desvio padrão; (b) $A_{1}$ a $A_{3}$ : amostras coletadas na área $A$; (c) $B_{1}$ a $B_{7}$ : amostras coletadas na área $B$; (d) $C_{1}$ a $C_{4}$ : amostras coletadas na área $C$; (e) $C P_{1}$ a $\mathrm{CP}_{3}$ : contraprova da amostra de sedimentos (ALEXANDRE, 2006). 
No Estado de Minas Gerais, alguns estudos relacionados à contaminação por mercúrio (RAMOS; PEREIRA FILHO, 1996; DESCHAMPS et al., 1998; WINDMÖLLER et al., 2007, FEAM, 2005) vêm sendo realizados, sobretudo, em áreas de garimpo de ouro ativas e inativas. Como não foi possível estabelecer um valor de referência local para concentração de mercúrio em sedimentos na localidade em estudo, utilizaram-se alguns valores encontrados em locais com e sem a interferência antrópica, listados na Tabela 4, para fins de comparação. Pode-se observar, nessa tabela, que os valores encontrados neste estudo são compatíveis com os detectados na maioria dos sítios onde houve interferência antrópica.

É importante ressaltar, com base nos valores apresentados, que as concentrações de mercúrio detectadas nos sedimentos não são alarmantes, apesar de não poderem ser negligenciadas.

Quanto ao solo, estudos recentes têm indicado que este exerce importante papel no ciclo biogeoquímico do mercúrio, como reservatório e emissor para os diversos compartimentos da atmosfera (OLIVEIRA et al., 2007; AZEVEDO, 2003).
Observa-se na Tabela 5 que a avaliação da contaminação do solo indicou a presença de mercúrio nas áreas A, B e C, com concentrações superiores aos valores de referência de qualidade $\left(0,05 \mathrm{mg} \cdot \mathrm{kg}^{-1}\right)$ propostos pela CETESB (2005), mas abaixo dos valores de prevenção $(0,5$ $\mathrm{mg} \cdot \mathrm{kg}^{-1}$ ), exceto no ponto $\mathrm{C}_{1}$, em que se detectou, na quarta campanha, concentração de $0,55 \mathrm{mg} \cdot \mathrm{kg}^{-1}$. Considerando-se o valor de referência local estabelecido pela FEAM (2005) para a região $\left(0,3 \mathrm{mg} \cdot \mathrm{kg}^{-1}\right)$, todas as concentrações foram superiores a esse limite, à exceção do ponto $B_{5}$.

Estudos relacionados ao comportamento do mercúrio em compartimentos ambientais na Amazônia são realizados até hoje, já que esse elemento foi amplamente utilizado nessa região para recuperação de ouro de aluvião. Apesar da variabilidade das características do solo em diferentes locais, os valores obtidos neste trabalho são comparáveis aos encontrados em solos da região amazônica por Fadini e Jardim (2001) (0,081-0,320 mg.kg-1), Lechler et al. (2000) (0,2320,406 mg. $\left.\mathrm{kg}^{-1}\right)$ e Wasserman et al. (2007) $\left(0,05-0,25 \mathrm{mg} \cdot \mathrm{kg}^{-1}\right)$, e são maiores que os valores médios $\left(0,05-0,1 \mathrm{mg} \cdot \mathrm{kg}^{-1}\right)$ globais citados na literatura (FADINI; JARDIM, 2001).

Tabela 4 - Valores encontrados na literatura para concentração de mercúrio total em sedimentos de rio

\begin{tabular}{|c|c|c|c|}
\hline Local & $\begin{array}{l}\text { Mercúrio total } \\
\left(\mathrm{mg}^{\mathrm{kg}} \mathrm{kg}^{-1}\right)\end{array}$ & Característica & Referência \\
\hline Rio Preto/Bacia Paraíba do Sul (MG) & 0,12 & Área não contaminada & Ramose Pereira Filho $(1996)^{*}$ \\
\hline Rio Preto/Bacia Paraíba do Sul (MG) & 0,65 & Contaminação por atividade de garimpo & Ramose Pereira Filho (1996)* \\
\hline Córrego Tripuí/Bacia do Rio Doce (MG)** & 0,14 & Área não contaminada & Deschamps et al. (1998)* \\
\hline Rio do Carmo/Bacia do Rio Doce (MG)** & 0,20 & Contaminação por atividade de garimpo & Deschamps et al. (1998)* \\
\hline Córrego Tripuí/Bacia do Rio Doce (MG)** & 0,28 & Não contaminada, presença de cinábrio & Cruz (2002)* \\
\hline Monsenhor Horta/Mariana (MG) & $0,06-0,47$ & Área de garimpo abandonada e ativa & Windmöller et al. (2007) \\
\hline Antônio Pereira/Ouro Preto (MG) & $0,09-1,1$ & Área de garimpo, incluindo garimpo legal & Windmöller et al. (2007) \\
\hline Furquim/Mariana (MG) & $0,05-0,09$ & Área de garimpo desativado & Windmöller et al. (2007) \\
\hline Bandeirantes/Mariana (MG) & $0,05-0,11$ & Área de garimpo abandonada e ativa & Windmöller et al. (2007) \\
\hline Quadrilátero Ferrífero (MG) & $0,16-4,6$ & $\begin{array}{l}\text { Ribeirões do Carmo, Tripuí e do Funil; } \\
\text { Rio Gualaxo do Sul }\end{array}$ & Ramos (2005) \\
\hline Córrego Rico/Descoberto (MG) & $0,18-0,46$ & Área próxima ao afloramento de mercúrio & Feam (2005) \\
\hline Ribeirão do Grama/Descoberto (MG) & 0,06 & $\begin{array}{l}\text { Área a jusante do afloramento de } \\
\text { mercúrio e aparentemente não } \\
\text { contaminada (FEAM, 2005) }\end{array}$ & Feam (2005) \\
\hline Ribeirão do Grama/Descoberto (MG) & $0,02-0,51$ & $\begin{array}{l}\text { Área a jusante e distante do } \\
\text { afloramento de mercúrio }\end{array}$ & Alexandre (2006) \\
\hline
\end{tabular}

Fonte: Adaptado de FEAM (2005).

${ }^{*}$ citado pela FEAM (2005); **mediana.

Tabela 5 - Concentração de mercúrio total no solo

\begin{tabular}{|c|c|c|}
\hline \multirow[t]{2}{*}{ Amostras } & \multicolumn{2}{|c|}{ Concentração (mg.kg $\left.{ }^{-1}\right)^{(a)}$} \\
\hline & $3^{a}$ Campanha & $4^{\mathrm{a}}$ Campanha \\
\hline $\mathrm{A}_{3}^{(\mathrm{b})}$ & - & $0,33 \pm 0,01$ \\
\hline $\mathrm{B}_{5}^{(\mathrm{c})}$ & - & $0,26 \pm 0,02$ \\
\hline $\mathrm{C}_{1}{ }^{(\mathrm{d})}$ & $0,40 \pm 0,04$ & $0,55 \pm 0,03$ \\
\hline
\end{tabular}

(a) média de três repetições \pm desvio padrão; (b) $A_{3}$ amostra coletada na área $A$; (c) $B_{5}$ : amostra coletada na área $B$; (d) $C_{1}$ : amostras coletadas na área $C$. 
Tabela 6 - Concentração de mercúrio total em peixes (área C)

\begin{tabular}{|c|c|c|c|c|c|c|}
\hline Campanha & $\begin{array}{l}\text { Nome } \\
\text { popular }\end{array}$ & $\begin{array}{c}\text { Nome } \\
\text { científico }\end{array}$ & $\begin{array}{l}\text { Nível } \\
\text { trófico }\end{array}$ & $\begin{array}{l}\text { Massa } \\
(\mathrm{g})\end{array}$ & $\begin{array}{l}\text { Comprimento } \\
\text { (cm) }\end{array}$ & $\begin{array}{l}\text { Concentração } \\
\left(\mathrm{mg} \cdot \mathrm{kg}^{-1}\right)^{\star}\end{array}$ \\
\hline \multirow{2}{*}{$2^{\mathrm{a}}$} & Acará & Geophagus brasiliensis & Onívoro & 10,5 & 8,2 & $0,15 \pm 0,02$ \\
\hline & Lambari & Astyanax scabripinnis & Onívoro & 12,0 & 8,5 & $0,04 \pm 0,01$ \\
\hline \multirow{3}{*}{$4^{\mathrm{a}}$} & Acará & Geophagus brasiliensis & Onívoro & 12,7 & 8,8 & $0,15 \pm 0,01$ \\
\hline & Lambari & Astyanax scabripinnis & Onívoro & 12,2 & 8,9 & $0,05 \pm 0,01$ \\
\hline & Traíra & Hoplias malabaricus & Carnívoro & 174,3 & 25 & $0,08 \pm 0,01$ \\
\hline
\end{tabular}

*Média de três repetições \pm desvio padrão.

As concentrações de mercúrio em peixes (Tabela 6) mantiveram-se abaixo do limite máximo estabelecido pela portaria Anvisa 685/1998 de 0,5 mg. $\mathrm{kg}^{-1}$ para não predadores e 1,0 mg. $\mathrm{kg}^{-1}$ para predadores e abaixo do limite estabelecido pela WHO (1991) para consumo frequente $\left(0,30 \mathrm{mg} \cdot \mathrm{kg}^{-1}\right)$.

Wasserman et al. (2007) analisaram espécies de peixes em viveiros situados em propriedades do sul da Amazônia, que foram expostas à mineração, e verificaram que exemplares das espécies Hoplias malabaricus (traíra) pesando 0,2 kg e de Geophagus brasiliensis (acará) com 0,1 $\mathrm{kg}$ apresentaram mercúrio em concentrações de 0,31 e 0,09 mg. $\mathrm{kg}^{-1}$, respectivamente - valores comparáveis aos apresentados na Tabela 6 .

Neste trabalho, das espécies onívoras analisadas, as maiores concentrações de mercúrio foram encontradas nas amostras de Geophagus brasiliensis (acará), possivelmente devido a hábitos dessa espécie que podem ter contribuído para a acumulação desse elemento. Esses peixes têm preferência por remansos ou margens com vegetação abundante e ingerem ampla variedade de alimentos de fundo de rio. Acredita-se que concentrações de mercúrio mais acentuadas seriam detectadas em espécimes maiores, uma vez que esses valores aumentam com a idade da espécie, que pode ser avaliada por seu comprimento (AZEVEDO, 2003).

O exemplar da espécie carnívora, Hoplias malabaricus (traíra), selecionado com o intuito de verificar a biomagnificação, apresentava pequenas dimensões e baixo peso, em comparação com os valores máximos que a espécie pode atingir. Espécimes mais desenvolvidos permitiriam verificar a máxima biomagnificação e biodisponibilidade nos peixes desse ecossistema.

\section{Conclusões}

Fatos históricos indicam que as atividades de exploração de ouro no município de Descoberto, na Zona da Mata do Estado de Minas Gerais, foram desenvolvidas com o uso de amalgamação desse metal, o que resulta em perdas elevadas de mercúrio para o meio ambiente e que, provavelmente, deu origem à contaminação da bacia do ribeirão do Grama.

Como conclusão geral deste trabalho, pode-se afirmar que existe mercúrio no solo, nos sedimentos e na água, em quantidades significativas, nas áreas estudadas da bacia do ribeirão do Grama, em comparação com níveis do metal detectados em locais que sofreram interferência antrópica. Dessa forma, provavelmente a exploração de ouro ocorrida no passado, com o uso de mercúrio metálico na amalgamação, elevou os níveis de mercúrio nos compartimentos ambientais em diversas localidades da bacia.

Existem concentrações elevadas de mercúrio nos solos $(0,26$ a $\left.0,55 \mathrm{mg} \cdot \mathrm{kg}^{-1}\right)$, em sedimentos $\left(0,13\right.$ a $\left.0,61 \mathrm{mg} \cdot \mathrm{kg}^{-1}\right)$ e na água $(<0,2$ a $\left.2,10 \mu \mathrm{g} . \mathrm{L}^{-1}\right)$. Nos peixes analisados, não foram detectadas concentrações acima do permitido pela legislação brasileira (ANVISA, 1998).

Tomando por base valores de concentrações desse elemento em sedimentos de outras regiões da Zona da Mata mineira, as concentrações de mercúrio detectadas nos sedimentos estudados, apesar de não alarmantes, não podem ser negligenciadas.

Em relação à contraprova dos resultados obtidos nas análises de sedimentos por Alexandre (2006), não foram observadas diferenças significativas nas concentrações do elemento nos dois estudos.

Não foi possível estabelecer valores de referência local para a bacia do ribeirão do Grama, uma vez que a área selecionada como controle apresentou elevadas concentrações de mercúrio no solo e nos sedimentos.

Atualmente, a área em que ocorreu o afloramento encontra-se classificada como contaminada no "Inventário de áreas suspeitas de contaminação e contaminadas do Estado de Minas Gerais 2009", com projeto de intervenção elaborado. Recomenda-se que, além das ações de intervenção na área do foco inicial do afloramento, seja realizado o monitoramento da concentração de mercúrio nos corpos de água, solo e sedimentos da bacia do ribeirão do Grama, para verificar se as concentrações de mercúrio se mantêm estáveis no decorrer dos anos e para que sejam estabelecidos valores de referência para os sedimentos e solos da região, além de análises de mercúrio em espécimes de peixes mais desenvolvidos; por fim, recomenda-se que se verifique a possibilidade de existência de outros focos de contaminação, já que há indícios de que a atividade de garimpo ocorreu em diversos pontos da região.

\section{Agradecimentos}

Ao Conselho Nacional de Desenvolvimento Científico e Tecnológico (CNPq), à Fundação de Amparo à Pesquisa do Estado de Minas Gerais (FAPEMIG) e à Coordenação de Aperfeiçoamento de Pessoal de Nível Superior (CAPES), pelo apoio financeiro na forma de projetos de pesquisa e pela bolsa de Mestrado concedida à primeira autora. 


\section{Referências}

ALEXANDRE, S.C. Caracterização de área contaminada por mercúrio em Descoberto-Minas Gerais. Dissertação (Mestrado), Universidade Federal de Viçosa, Viçosa, MG, 2006.

APHA, AWWA, WEF. Standard methods for the examination of water and wastewater. 19. ed. Washington: APHA, AWWA, WEF, 1995.

AGÊNCIA NACIONAL DE VIGILÂNCIA SANITÁRIA (ANVISA). Portaria No 685, de 27 de agosto de 1998. 1998. Disponível em: <http://www. anvisa.gov.br/legis/portarias/685_98.htm >. Acesso em: maio 2006.

AZEVEDO, F.A. Toxicologia do mercúrio. São Carlos: Rima, 2003.

COMPANHIA DE TECNOLOGIA DE SANEAMENTO AMBIENTAL (CETESB). Decisão de Diretoria no. 195-2005-E, de 2005, de 23 de novembro de 2005. 2005. Disponível em <http://www.cetesb.sp.gov.br/ Solo/relatorios/tabela valores 2005.pdf >. Acesso em: maio 2007.

CONSELHO NACIONAL DO MEIO AMBIENTE (CONAMA). Resolução no. 344, de 25 de março de 2004. 2004. Disponível em <http://www. mma.gov.br/port/conama/res/res04/res34404.xml>. Acesso em: junho 2007

. Resolução nº. 357, de 17 de março de 2005. 2005. Disponível em: <http://www.mma.gov.br/conama/res/res05/res35705.pdf >. Acesso em: junho 2007.

CRUZ, L.V. Avaliação geoquímica ambiental da Estação Ecológica do Tripuí e adjacências, sudeste do quadrilátero ferrífero - MG. Dissertação (Mestrado em Geoquímica Ambiental), Universidade Federal de Ouro Preto, Ouro Preto, MG, 2002.

DESCHAMPS, E. et al. Pesquisa da contaminação por mercúrio em garimpo do Estado de Minas Gerais, seu impacto na saúde e no meio ambiente. Belo Horizonte: FEAM, v. 1. (Relatório Técnico Final), 1998

FADINI, P.S.; JARDIM, W.F. Is the Negro River Basin (Amazon) impacted by naturally occurring mercury? The Science of the Total Environment, v. 275, n. 1-3, p. 71-82, 2001.

FUNDAÇÃO ESTADUAL DO MEIO AMBIENTE (FEAM). Diagnóstico da contaminação ambiental em Descoberto, Minas Gerais, em decorrência do afloramento de mercúrio em dezembro de 2002. (Relatório de progresso). Belo Horizonte: CDTN, 2005

Inventário de áreas suspeitas de contaminação e contaminadas do Estado de Minas Gerais. Disponível em: <http://www.feam.br/images/ stories/alvaro/inventario\%20areas\%20susp_cont_e cont 2009.pdf >

LECHLER, P.J. et al. Elevated mercury concentrations in soils, sediments, water, and fish of the Madeira River basin, Brazilian Amazon: a function of natural enrichments? The Science of the Total Environment, v. 260, n. 1-3, p. 87-96, 2000.
LIMA, A.C.G. Monitoramento da qualidade das águas na Bacia do Rio Botafogo, em Pernambuco, com ênfase para a concentração de mercúrio total em águas e sedimentos. Dissertação (Mestrado Gestão Ambiental), Universidade Federal de Pernambuco, Recife, PE, 2005.

MALM, O. et al. Utilização do acessório de geração de vapor frio para a análise de mercúrio em investigações ambientais por espectrofotometria de absorção atômica. Revista Ciência e Cultura, n. 41, v. 1, p. 88-92, 1989

MARINS, R.V. et al. Distribuição de mercúrio total como indicador de poluição urbana e industrial na costa brasileira. Química Nova, v. 27, n. 5, p. $763-770,2004$

MARINS, R.V.; PARAQUETTI, H.H.M.; AYRES, G.A. Alternativa analítica para especiação físico-química de mercúrio em águas costeiras tropicais. Química Nova, v. 25, n. 3, p. 372-378, 2002.

MARQUES, E.A.G. Relatório de projeto de pesquisa - caracterização de área contaminada por mercúrio no Município de Descoberto, MG, 2007.

OLIVEIRA, L.C. et al. Distribuição de mercúrio em diferentes solos da Bacia do Médio Rio Negro-AM: influência da matéria orgânica no ciclo biogeoquímico do mercúrio. Química Nova, v. 30, n. 2, p. 274-280, 2007.

RAMOS, W.E.S. Contaminação por mercúrio e arsênio em ribeirões do quadriláteroferrífero-MG, emáreas de mineração eatividades garimpeiras. Dissertação (Mestrado em Agroquímica), Universidade Federal de Viçosa, Viçosa, MG, 2005.

RAMOS, A.J.L.A.; PEREIRA FILHO, S.R. Diagnóstico preliminar das áreas submetidas à garimpagem de ouro em Rio Preto - MG. Rio de Janeiro: CETEM/CNPq, 1996.

VIEIRA, J.L. F.; PASSARELLI, M.M. Determinação de mercúrio total em amostras de água, sedimentos e sólidos em suspensão de corpos aquáticos por espectrofotometria de absorção atômica com gerador de vapor a frio. Revista de Saúde Pública, v. 30, n. 3, p. 256-260, 1996.

TOMAZELLI, A.C. Estudo comparativo das concentrações de cádmio, chumbo e mercúrio em seis bacias hidrográficas do Estado de São Paulo. Tese (Dourado em Biologia Comparada), Universidade de São Paulo, Ribeirão Preto, 2003.

WASSERMAN, J.C. et al. Mercury in soils and sediments from gold mining liabilities in Southern Amazonia. Química Nova, v. 30, n. 4, p. 768-773, 2007.

WINDMÖLLER, C.C. et al. Distribuição e especiação de mercúrio em sedimentos de áreas de garimpo de ouro do Quadrilátero Ferrífero (MG). Química Nova, v. 30, n. 5, p. 1088-1094, 2007.

WORLD HEALTH ORGANIZATION (WHO). Inorganic mercury. Environmental Health Criteria, Geneva, v. 118, 1991. 